\title{
FORMAR UM HOMEM PARA O MEIO RURAL EM BENEFÍCIO \\ DO DESENVOLVIMENTO NACIONAL: RURALISMO PEDAGÓGICO NA ESCOLA NORMAL RURAL DE JUAZEIRO DO NORTE*
}

Antonio Germano Magalhães Junior ${ }^{* *}$

\section{RESUMO}

O objetivo deste estudo é compreender a constituição das práticas pedagógicas ruralistas na Escola Normal Rural de Juazeiro do Norte, cidade interiorana do Estado do Ceará, práticas escolares que se diferenciavam de outras instituições formadoras de professoras do meio urbano. As fontes de pesquisa utilizadas foram: o Jornal O Lavrador, tendo sido localizados 112 exemplares, publicado de maneira irregular, entre as décadas de 1930 e 1970; os Anais da Semana Ruralista de Juazeiro do Norte e entrevistas a alunos(as) das três primeiras turmas da escola. O referencial teórico-metodológico se fundamenta na história do cotidiano, em especial nos escritos de Michel de Certeau (1996). Constatou-se que o cotidiano escolar representado nas práticas pedagógicas e produtos materiais específicos que proporcionavam uma formação diferenciada para o meio rural, se constituíam através de relações que determinavam seus termos e que cada individualidade era um lugar onde atuava uma pluralidade incoerente de suas determinantes relacionais.

PALAVRAS CHAVE: Cotidiano. Escola Normal Rural. Práticas Ruralistas.

\footnotetext{
${ }^{*}$ Versão modificada e ampliada do trabalho apresentado em 21 de junho de 2008 na mesa coordenada intitulada "Escolas, escolarizações e utensilagens materiais" no VII Congresso Luso-Brasileiro de História da Educação realizado na Universidade do Porto, Portugal.

** Doutor em Educação pela Universidade Federal do Ceará e Professor de História da Educação Brasileira no Curso de Pedagogia da Universidade Estadual do Ceará. E-mail: germanomjr@yahoo.com.br
} 


\begin{abstract}
The objective of this study is understand the constitution of the rural pedagogic practices in the Normal Rural School of Juazeiro do Norte, school practices that were differentiated of other forming institutions of teachers of the urbane way. The fountains of inquiry used were: the Newspaper O Lavrador, having been located 112 examples, published in irregular way, between the decades of 1930 and 1970; the Annals of the Rural Week of Juazeiro do Norte and the interviews done with the students of the three first groups of the school. The referential system theoretician is based on the history of the daily life, in special written of Michel de Certeau (1996). It was noticed that the school daily life represented in the pedagogic practices and specific material products that were providing a differentiated formation for the rural way, that it was constituted through relations that determines his terms and that each individuality was a place where an inconsistent plurality of his relational determinants.
\end{abstract}

KEYWORDS: Daily life. Normal Rural School. Rural Practices.

No Brasil, sob o governo de Getúlio Dorneles Vargas (1930 a 1945 e, depois, de 1950 a 1954), a escola assumia um importante papel na constituição de uma consciência concomitantemente modernizante e conservadora, em que se pregava o apego ao "meio" e, ao mesmo tempo, pressupunha-se uma ação eficiente, autônoma, racional e produtiva, no contexto desse mesmo "meio".

A necessidade de manter o homem no campo se articulava à constituição de escolas que, por meio de práticas que reproduzissem e aprimorassem o cotidiano do meio rural, caracterizavam-se como instituições educacionais adaptadoras do homem. Havia a intencionalidade de formar professores que diferiam dos pertencentes às escolas do meio urbano, pois deveriam possuir e transmitir conhecimentos que estivessem em sintonia com as necessidades do meio rural.

O objeto desta investigação é a cotidianidade educacional, seus objetos materiais e as práticas pedagógicas ruralistas na Escola Normal Rural de Juazeiro do Norte (ENRJN), instalada em 13 de março de 1934.

Educ. e Filos. Uberlândia, v. 23, n. 46, p. 99-118, jul./dez. 2009. 
A criação da primeira instituição educacional de formação de professores para o meio rural antecede dois marcos da política ruralista do governo getulista, a Macha para o Oeste (1938) e o Oitavo Congresso Brasileiro de Educação (1942). A demarcação temporal aqui estabelecida representa os anos de formação das três primeiras turmas da referida escola, que teve seu ato inaugural em 1934, sendo o ano 1939 o marco das festividades de formatura da terceira turma. Acredita-se que as três primeiras turmas representaram a constituição do modelo de formação ruralista exercitado nas turmas que posteriormente ingressaram na escola, respeitando as particularidades que cada temporalidade constitui nas tramas cotidianas. $\mathrm{O}$ objetivo deste estudo é compreender a constituição das práticas pedagógicas ruralistas na ENRJN.

A proposta de uma escola de formação de professores para o meio rural nasceu consorciada com os ideais da "ruralização do ensino", pensamento propagado na primeira metade do século XX por pensadores sociais como Sílvio Romero, Alberto Torres, o sanitarista Belizário Pena e Sud Mennucci (LOURENÇO FILHO, 2001). Houve, no início da década de 1930, debates sobre o assunto no cenário nacional, e é possível perceber no pronunciamento de Joaquim Moreira de Sousa em 1931, no IV Congresso Nacional de Educação. Este lembra que, naquele momento, consolidaramse as idéias dos pioneiros do ruralismo pedagógico, os quais defendem:

Uma escola rural típica, acomodada aos interesses e necessidades da região a que fosse destinada [...] 'que impregnasse o espírito do brasileiro, antes mesmo de the dar a técnica do trabalho racional no amanhã dos campos, de alto e profundo sentido ruralista, capaz de nortear a ação para a conquista da terra dadivosa e de seus tesouros, com a convicção de encontrar o enriquecimento próprio e do grupo social de que faz parte' (isto em oposição à 'escola literária' que desenraizava o homem do campo) (THERRIEN; DAMASCENO, 1993, p. 18).

A Escola surgiu da intenção de "[...] habituar o educando a viver, autenticamente, o trabalho discente e a conviver, adquirindo usos sadios, no sentido físico e no intelectual" (SOUSA, 1961, p. 169), juntamente com um sonho do Pe. Cícero Romão Batista, líder religioso e político da 
região do Cariri, em ter uma escola de formação de professores na cidade de Juazeiro do Norte. A iniciativa juntava necessidade, sonho e vontade de educar em uma ação verdadeiramente cruzadista. Nessa direção também sinalizava Plácido Aderaldo Castelo, que atuava como juiz da região, ao justificar a necessidade da Escola Normal Rural de Juazeiro do Norte:

Para modificarmos essa mentalidade, herança da época da escravidão, precisamos de realizar campanhas como a que empreendeu e levou a efeito a Sociedade dos Amigos de Alberto Torres, a fim de que governo e governados despertem e, numa cooperação eficiente, promovam a transformação do ensino escolar normal, habilitando pioneiros para a nova cruzada de reabilitação do Brasil (CASTELO, 1951, p.6).

O Movimento Ruralista possuía defensores que acreditavam e propagandeavam a necessidade de desenvolvimento do campo para o progresso na nação. A ideologia da salvação através do campo era defendida associada à crença em uma "tendência natural" do Brasil ao desenvolvimento da economia através da agricultura. Para que pudéssemos colocar em prática o desenvolvimento do país através da vida campesina, deveríamos possuir uma escola devidamente adequada ao exercício das práticas de uma agricultura produtiva.

O Brasil dos primeiros anos do século XX vivenciava um crescimento desordenado do meio urbano, causando tensões sociais, e possuía uma escola eminentemente voltada para a formação do homem citadino. Vivenciávamos o crescimento econômico das cidades, atraindo os campesinos para os sonhos de uma vida "moderna", em que os ideais de progresso se materializavam nos discursos dos educadores dentro dos estabelecimentos de ensino. Não havia unanimidade de otimismo em relação ao desenvolvimento das cidades em detrimento de uma vida produtiva no campo. Educadores como Sud Mennuci defendiam políticas de implantação e desenvolvimento de escolas voltadas para formação do homem do campo, através da valorização de práticas agrícolas modernas (MENNUCCI, 1944; 1935; 1934).

A ruralização do ensino, portanto, constituiu-se no ideário que deu sustentação à proposição de uma Escola Normal Rural no Ceará, cujo 
[...] sentido fundamental [...] era que a escola localizada no sertão se transformasse, de escola comum, vasada em moldes gerais e muitas vezes inadequados às condições locais, em uma instância concreta de adaptação imediata escolar às exigências da vida em sua região. A intenção era substituir o livresco e abstrato que havia nas escolas tradicionais, mesmo as localizadas no sertão, por um aprendizado autênticamente útil às necessidades dos membros de uma comunidade rural (SOUSA, 1961, p.168).

A constituição de um estabelecimento educacional, portanto, realiza-se por meio de um misto de muitos elementos, podendo perpassar necessidades, sonhos, iniciativas pessoais e coletivas; muitas justificativas podem ser apresentadas e acreditamos que na escola em estudo não foi diferente.

A política ruralista encontrou na cidade de Juazeiro do Norte, no interior do Estado do Ceará, uma população que precisava de uma escola de formação de professores, pessoas que estavam interessadas e adequadas às condições locais preparadas para o empreendimento. Certamente, os relatos daqueles que recebem os títulos de idealizadores deixaram documentada uma forma particular de descrever os acontecimentos.

Muitos foram os que participaram da criação da referida instituição educacional e, em especial, a personagem Amália Xavier merece nossa atenção devido ter deixado escrito farta descrição do cotidiano da ENRJN. Na posição de diretora, Amália Xavier de Oliveira, ao escrever a História da Escola Normal Rural de Juazeiro do Norte (1984), encontrava-se permeada pelas forças do seu tempo, com desejos, valores, necessidades e verdades que marcavam sua existência. Não podemos interpretar os escritos de seu livro sem contextualizarmos suas memórias e seu cotidiano. Amália Xavier, ao situar o cenário em que sucedeu a criação da referida instituição, apresenta uma descrição minuciosa, repleta de características de uma escrita narrativa e valorativa de pessoas reconhecidas como ilustres, uma escrita sem problematizações ou análises mais críticas.

As produções historiográficas da época, em que a escola foi criada, apresentam personagens que ocupavam cargos de destaque político ou econômico. Um deles era Plácido Aderaldo Castelo, destacado por Amália Xavier como articulador do empreendimento que assegurou a 
localização deste estabelecimento em Juazeiro do Norte. Castelo detalha como os interessados nesta causa se articularam visando à viabilização das condições necessárias para ali alocá-lo. De acordo com sua descrição:

Em o dia 9 de dezembro de 1933, na Sala das Audiências do Juízo Municipal, reuniu-se o Conselho Escolar, sob nossa presidência. Explicamos a finalidade da sessão: constituir uma sociedade de finalidades educacionais e encampar a Escola Normal Rural, conforme o esboço do decreto já publicado. Todos os presentes concordaram com a idéia. Na sessão seguinte, 13 do mesmo mês, eram lidos, discutidos e aprovados os Estatutos e subscritas as cotas necessárias para a constituição do Capital: trinta mil contos de réis, hoje mil cruzeiros. Registrados os Estatutos e observadas as formalidades legais, ficou sendo denominada a nova sociedade - Instituto Educacional ${ }^{1}$, estabelecendo o artigo 10, VIII, que a diretoria ficava autorizada "a assinar contratos com o governo por intermédio do diretor para tal designado, no sentido de ser encampada pela sociedade, a Escola Normal Rural, do Estado, nos moldes do esboço do decreto publicado na imprensa com as alterações julgadas necessárias pelos contratantes". Tal designação recaiu na pessoa da professora Amália Xavier de Oliveira, que se achava comissionada pelo governo, e tesoureira do Instituto. Os esforços no sentido da constituição da sociedade foram apreciáveis (CASTELO, 1970, p. 226-227).

A ENRJN tornou-se modelo de experiência ruralista em todo o país, diferenciando-se de outras escolas de formação de professores devido às práticas ruralistas empreendidas na instituição e a uma proposta curricular que objetivava formar professores capazes de formar o homem do campo

1 De acordo com Boaventura de Souza (1994, p. 31), são sócios fundadores dessa entidade: Dr. Plácido Aderaldo Castelo, Adília Sobreira, José Francisco da Graça, Francisco Néri da Costa Morato, Amália Xavier de Oliveira, José Bezerra de Menezes, Nair Figueredo, Elza Figueredo, José Hermínio Amorim, José Pedro da Silva, José Pereira da Silva, Dr. Manuel Belém de Figueredo, José Geraldo da Cruz, Dr. Jacinto Botelho, Dr. Mozart Cardoso de Alencar, Padre Cícero Romão Batista, Dr. Batista, Dr. Juvêncio Santana e Doroteu Sobreira. Ainda de acordo com o autor, "[...] coube ao Pe. Cícero grande parcela na criação do patrimônio do Instituto Educacional de Juazeiro do Norte para que se criasse a primeira Escola Normal Rural do Brasil” (Ibidem, p. 28).

Educ. e Filos. Uberlândia, v. 23, n. 46, p. 99-118, jul./dez. 2009. 
necessário à "redenção" e ao progresso nacional. O plano de estudos da Escola Normal Rural de Juazeiro do Norte, de acordo com o do Decreto ${ }^{\circ}$ 1.218/1934 (Art. $5^{\circ}$ ), era composto por três cursos²: o Primário, com duração de 5 anos; o Complementar ${ }^{3}$, com duração de 2 anos; e o Normal Rural, com duração de 3 anos. Estes dois últimos estão diretamente relacionados com a formação do professor ruralista.

As finalidades desse estabelecimento de ensino, cujo regime de funcionamento previa desde o internato, o semi-internato, até o externato, estão assim definidas no Regulamento no Capítulo I (Art. $1^{\circ}$ ):

a) - preparar os professores de ensino primario das zonas rurais do Estado, de maneira a torná-los aptos a orientar, racionalmente, as novas gerações nas tarefas agricolas, dando-lhes a conhecer os meios de defesa de saúde e de incentivo ao progresso, no campo;

b) - contribuir, pelo preparo conveniente do professor, para que a escola primaria rural se torne um centro de iniciações economicas e profissional, com acentuada influencia civilizadora, sobre toda a comunidade do lugar, onde estiver;

c) - dar, pelo professor que preparar, consciencia agricola e sanitaria às populações rurais, além de exata compreensão do valor da previdencia e da economia, como condição de felicidade, individual e coletiva;

\footnotetext{
${ }^{2} \mathrm{O}$ Artigo $5^{\circ}$ estabelece: “Anexo ao curso normal, haverá um curso complementar e um primário nos moldes dos já existentes na Escola Normal Pedro II". Muito embora o Grupo Rural Modelo seja oficialmente anexo a Escola Normal Rural de Juazeiro do Norte somente em 06 de fevereiro de 1936 por ato do governo de Menezes Pimentel, o Curso Primário é ofertado por esta instituição desde o início de suas atividades. É o que deixa claro Amália Xavier de Oliveira (1984, p. 24) ao registrar que, em 17 de março de 1934, momento em que ocorre a primeira aula do Curso Complementar, "anexo" a este curso "funcionaram também 4 classes primárias".

${ }^{3}$ A expressão "Curso Complementar" é empregada no decreto de criação da Escola Normal Rural de Juazeiro do Norte, sendo também presente nos escritos de Amália Xavier (1984); todavia, noutros textos, observam-se denominações diferenciadas. Este é o caso de Lourenço Filho (2001) que utiliza a denominação "Curso Intermediário" para referir-se ao Curso Complementar. Em José Boaventura de Souza (1994, p. 34), por sua vez, encontramos a seguinte referência: "A escola foi organizada em dois ciclos: o primeiro em dois anos após o primário e era denominado "Básico". O segundo, em três anos, denominado "Normal Rural".
}

Educ. e Filos. Uberlândia, v. 23, n. 46, p. 99-118, jul./dez. 2009. 
d) - despertar, por meio do professor, nos futuros plantadores e criadores, e, ainda, nos atuais, a consciencia do valor de sua classe que, organizada e liberta de toda influencia dominadora extranha, deve colaborar, ao lado das demais classes, no engrandecimento e governo do país.

O Curso Complementar, que antecedia o Curso Normal Rural, visava à preparação dos educandos para a formação docente. De acordo com Lourenço Filho (2001, p. 83), a organização curricular desta etapa intermediária da formação apresentava as seguintes disciplinas: Matemática, Geografia, Francês, Música, Educação Física, Desenho, Trabalhos Manuais, Práticas Agrícolas, Português e História do Brasil. O Quadro a seguir mostra a distribuição desses componentes curriculares durante o período de duração do curso:

TABELA1

Disciplinas do Curso Complementar da ENRJN

\begin{tabular}{|l|l|}
\hline \multicolumn{2}{|c|}{ Curso Intermediário } \\
\hline $\mathbf{1}^{\mathbf{0}}$ Ano & $\mathbf{2}^{\mathbf{0}}$ Ano \\
\hline Matemática & Português \\
\hline Geografia & Matemática \\
\hline Francês & História do Brasil \\
\hline Música & Francês \\
\hline Educação Física & Música \\
\hline Desenho & Educação Física \\
\hline Trabalhos Manuais & Desenho \\
\hline Práticas Agrícolas & Trabalhos Manuais \\
\hline-------- & Práticas Agrícolas \\
\hline
\end{tabular}

Fonte: Lourenço Filho, 2001.

Observa-se, na organização curricular do Curso Complementar, duas disciplinas ligadas à prática agrícola, presença que evidencia a preocupação em iniciar o candidato ao Curso Normal Rural nas questões e fainas ligadas ao meio rural. Note-se ainda que, além do aprendizado pela prática, predominavam disciplinas teóricas, e até mesmo aula de francês, indicando certo grau de erudição e a interferência dos padrões culturais predominantes da época no Ceará.

Educ. e Filos. Uberlândia, v. 23, n. 46, p. 99-118, jul./dez. 2009. 
O Curso Normal, que habilitava os professores ruralistas, de acordo com o Regulamento da Escola (Artigo $4^{\circ}$ ), compreendia as seguintes disciplinas: Língua Vernácula, Matemática, Fisiografia, Antropogeografia e História do Brasil, Ciências Físicas e Naturais, Educação Sanitária, Psicologia Educacional e Metodologia, Agricultura, Educação Econômica, Desenho e Trabalhos Manuais e Música e Cultura Física. A distribuição dessas disciplinas em três anos era feita conforme mostra o quadro a seguir:

TABELA 2

Disciplinas do Curso Normal Rural da ENRJN

\begin{tabular}{|l|l|l|}
\hline \multicolumn{1}{|c|}{$\mathbf{1}^{\mathbf{0}}$ Ano } & \multicolumn{1}{|c|}{$\mathbf{2}^{\mathbf{0}}$ Ano } & \multicolumn{1}{c|}{$\mathbf{3}^{\mathbf{0}}$ Ano } \\
\hline Língua vernácula & Língua Vernácula & Educação Sanitária \\
\hline Matemática & Matemática & $\begin{array}{l}\text { Psicologia Educacional e } \\
\text { Metodologia }\end{array}$ \\
\hline $\begin{array}{l}\text { Noções de Fisiografia geral } \\
\text { e especial do Brasil }\end{array}$ & Fisiogeografia do Brasil & $\begin{array}{l}\text { Agricultura e Indústrias } \\
\text { Rurais }\end{array}$ \\
\hline Historia do Brasil & Antropogeografia & Educação econômica \\
\hline Antropogeografia & Ciências Físicas e naturais & $\begin{array}{l}\text { Desenho e Trabalhos } \\
\text { Manuais }\end{array}$ \\
\hline $\begin{array}{l}\text { Desenho e trabalhos } \\
\text { manuais }\end{array}$ & $\begin{array}{l}\text { Desenho e Trabalhos } \\
\text { Manuais }\end{array}$ & Música e Cultura Física \\
\hline Música e Cultura Física & Música e Cultura Física & $-\mathrm{x}-$ \\
\hline
\end{tabular}

Fonte: Anais da Semana Ruralista de Juazeiro - Anexos (1935, p. 151-152).

À primeira vista, a distribuição desses componentes curriculares, sobretudo nos dois primeiros anos do Curso Normal Rural, denota certa ênfase na formação teórica, pois apenas a disciplina Desenho e Trabalhos Manuais indica a realização de atividades práticas por parte dos alunos. Esta impressão se fortalece quando se observa o $3^{\circ}$ ano, composto de disciplinas direcionadas para a vida no campo do professor ruralista, tais como: Noção de Sanitarismo, Psicologia da Educação, Conhecimentos sobre a Agricultura e Economia.

Segundo Souza (1994, p. 34), todavia, o desenho curricular 
"comportava uma carga horária de 2.420 horas distribuídas em aulas semanais". O referido autor esclarece a dinâmica curricular do Curso Normal Rural, ao ressaltar que a prática educativa da escola era organizada nos turnos manhã e tarde. No segundo turno do dia, eram realizadas atividades práticas, isto é, "para cada aula teórica no período da manhã" eram vivenciadas "aulas práticas no campo ou atividades nas [...] pequenas indústrias, artes e educação doméstica com cursos de Desenho, Corte e Costura e Arte Culinária" (Ibidem, p. 35).

Embora seja registrado como 13 de março de 1934, o dia da realização do seu primeiro Exame de Admissão, logo que foi solicitada sua encampação, seus fundadores foram em busca de alunos, "mas não eram quaisquer alunos", destaca Iracema Magalhães ${ }^{4}$, aluna egressa da Escola:

Ah, eu fui porque eu vinha pra cá, estudar aqui em Fortaleza. Tava quase certo, mas então houve a fundação da Escola e as pessoas que fundaram como: Dona Amália, Dr. Belém, Dr. Plácido Castelo, foram eles os fundadores, e eles andavam nas casas das famílias em busca de alunos. [...], aí eu posso dizer que fui uma aluna fundadora, que entrei.

Forjada sob o discurso do compromisso com o progresso do campo, a ENRJN surgiu como uma instituição particular, por isso mesmo composta pelas filhas das "boas famílias" de Juazeiro do Norte e proximidades, à época. Eram famílias de comerciantes, agricultores, políticos etc. Como lembra Assunção Gonçalves, aluna e professora desse estabelecimento, "naquele tempo a escola era particular. Paga! Vinte e cinco mil reis por mês ${ }^{5}$. Era cara como todo!". Este fato ajuda a compreender o reduzido contingente que compôs a primeira turma do Curso Normal Rural, integrada por cinco mulheres, a saber: Heloisa Coelho de Alencar (Barbalha), Maria Martins Camelo (Missão Velha), Maria Moreira (Juazeiro), Ceci Borges (Caririaçu), Dacilde Cruz (Santana do Cariri) (OLIVEIRA, 1984, p. 82). Essas alunas, com exceção de Maria Moreira que fez, em 1934, o $2^{\circ}$ Ano

4 Entrevista realizada a Iracema Magalhães, ex-aluna da ENRJN, realizada em 2006 na residência da entrevistada.

${ }^{5} \mathrm{O}$ valor da mensalidade também pode ser encontrado na tabela do Jornal O Lavrador, $\mathrm{n}^{\circ} .1$, pág. 8, de 14 de agosto de 1934 .

Educ. e Filos. Uberlândia, v. 23, n. 46, p. 99-118, jul./dez. 2009. 
Complementar na Escola Normal Rural de Juazeiro do Norte, ingressaram nesse estabelecimento de ensino em 1935, quando iniciaram o $1^{\circ}$ Ano do Curso Normal Rural. Ceci Borges veio transferida do Colégio Santa Tereza, do Crato, onde realizou os dois anos do Curso Complementar; Heloisa Coelho de Alencar, Maria Martins Camelo e Dacilde Cruz foram beneficiadas por decisão governamental (Decreto $n^{\circ} 1239$, de $1^{\circ}$ de fevereiro de 1934) que admitia ao "primeiro ano normal rural, portadores de certificados de Concurso para a 4" Entrância" (OLIVEIRA, 1984, p. 40).

Analisando os documentos referentes à ENRJN, verificamos que a instituição ruralista diferenciava suas práticas em relação a outros estabelecimentos de formação para o magistério não somente pelo currículo permeado de disciplinas associadas à vida campesina, mas à ocorrência de atividades agrícolas, organização de eventos com temáticas associadas ao campo, confecção de jornais, folhetins, cartilhas e outros materiais impressos que abordavam temas e problemas do cotidiano dos viventes do meio rural. Nas fontes consultadas, inúmeras passagens confirmam a preocupação em assegurar práticas consorciadas aos estudos teóricos previstos na organização curricular da proposta formativa da Escola, como mostram as transcrições:

Alunos do $2^{\mathrm{a}}$ ano Complementar fazem um plantio de amendoim no Campo da escola [...]. A semente foi enviada pela Sociedade dos Amigos de Alberto Torres [...] (OLIVEIRA, 1984, p. 29);

A Escola Normal Rural de Joaseiro, tem organização propria, diferenciadas de todas as outras escolas formadoras de mestres no paiz... Em derredor do prédio, existe amplo terreno, cultivado pelos próprios alunos, onde se pratica a agricultura racional e onde se ciriam diversas espécies de animaes domenticos. Em departamentos próprios faz-se o aprendizado de pequenas industrias ruraes e caseiras e exercita-se o corpo discente em educação sanitária... (Jornal $O$ Lavrador, 1938, p. 6);

EXCURSÕES - Fizemos quatro no corrente ano. Uma a Barbalha, por ocasião da Semana Ruralista. Outra a um engenho, em 10 de agosto na qual observámos o processo de fabricação de rapaduras. Uma a Crato em 17 de setembro e outra a São Pedro do Cariri, em 7 de outubro. Fizemos outras excursões [...] mesmo no município, sendo 
que em uma delas, a de Malvas, fizemos a extinção de um enorme formigueiro que atacava as culturas do clube de Malvas. (ANAIS da Semana Ruralista de Juazeiro, 1935, p. 42).

A promoção anual de concursos reunindo alunos em torno de um mesmo interesse, pode ser apontada como exercício das práticas ruralistas, sempre tentando associar a formação dos professores à vida no campo. Sobre o assunto, José Boaventura de Souza (1994, p. 37) faz uma descrição detalhada:

As atividades constavam sempre de uma parte principal, através de concursos sobre uma das diversas culturas da região [...] . Cada aluno tinha a tarefa de colecionar artigos, revistas, etc., e fazer o resumo das aulas referentes àquelas plantas. [...] Os principais concursos realizados eram em torno da: mandioca, algodão, cana-de-açúcar, arroz, feijão [...] Fruto destas iniciativas a escola com recursos próprios [...] construiu no seu campo agrícola: uma pocilga [...]; um galinheiro, um estábulo rústico, um pombal, um apiário. Cada classe tinha sob seus cuidados, uma dessas dependências, enfrentando todos os problemas que se relacionassem com a criação, sob sua responsabilidade. Diariamente, os chefes de turma anotavam no livro 'plantações e criações', todo ocorrido das diversas criações e no fim de cada ano, elaboravam um relatório geral [...].

Dentre as produções impressas que demonstram o cotidiano das práticas ruralistas da ENRJN está o jornal O Lavrador, por se tratar de uma publicação da própria escola, o periódico era “como 'animador' da causa ruralista, disseminava as idéias do movimento e o modus operandi, a partir de então, da formação de professores para o meio rural" (MAGALHÃES; FARIAS, 2007, p. 195). Seu conteúdo é constituído dos acontecimentos da escola e de assuntos relativos à vida do homem campesino. O Lavrador é, portanto, "rica fonte de informações, não somente de uma escola de formação de professores, mas também da sociedade que vivenciava momento particular da política brasileira, com os conflitos e jogos de poder". (Idem, p. 199).

Sistematizando os conteúdos trabalhados e as necessidades do trabalho com os afazeres campesinos, relacionando com a comunidade 
circundante da localidade em que estava instalada a escola, foram criadas instituições escolares, como o Clube Agrícola, a Liga da Amabilidade e Grêmio Literário Padre José de Anchieta, onde todos os associados envolvidos com o mesmo objeto de interesse trabalhavam com o intuito de fortalecer as bases do ruralismo, a sistematização dos conteúdos estudados e o trato com a comunidade. E também, por meio de palestras, discursos, relatórios e atividades práticas, demonstravam a manifestação do que foi apreendido dos trabalhos feitos em conjunto.

A realização de excursões permeava toda a vida estudantil dos futuros mestres ruralistas, por proporcionarem o exercício de atividades práticas, o conhecimento das experiências relacionadas à agricultura e outros assuntos de interesse da sociedade. Sobre a relevância do valor formativo, o relato de excursionistas registrados no jornal O Lavrador, de 1938, é enfático: "a Escola Normal Rural de Joazeiro, não poderia deixar de conceder aos seus professorandos, essas excursões tão cheias de sentido pedagógico, e, portanto, de real importância para os futuros educadores" (O Lavrador, 1938, p. 05).

O jornal $O$ Lavrador era utilizado cotidianamente como fonte de sistematização dos conteúdos trabalhados, propagador dos ideais e práticas ruralistas vivenciados na ENRJN.

TABELA 3

Excursões registradas pelo jornal $O$ Lavrador (1934-1946)

\begin{tabular}{|l|c|}
\hline Tema & Número de atividades \\
\hline Conclusão do Curso Normal Rural & 06 \\
\hline Inauguração de órgão público & 01 \\
\hline Visita em Instituições ligadas á agricultura & 06 \\
\hline Visita ao Horto do Padre Cícero (Religiosidade) & 01 \\
\hline Visita a campos agrícolas & 02 \\
\hline Total & 16 \\
\hline
\end{tabular}


TABELA 4

Práticas Agrícolas no Jornal O Lavrador (1934/1946)

\begin{tabular}{|l|c|}
\hline \multicolumn{1}{|c|}{ Tema } & $\mathbf{N}^{\mathbf{0}}$ de atividades \\
\hline Semeadura & 01 \\
\hline Plantio de diversas culturas & 13 \\
\hline Transplantação de árvores & 01 \\
\hline Relatórios das aulas de campo & 08 \\
\hline Combate a pragas do campo & 02 \\
\hline Pulverização de plantações & 02 \\
\hline \multicolumn{2}{|c|}{ Total } \\
\hline \multicolumn{2}{|c|}{}
\end{tabular}

TABELA 5

Matérias sobre Culinária, Corte e Costura no jornal O Lavrador (1934-1946)

\begin{tabular}{|l|l|}
\hline \multicolumn{1}{|c|}{ Identificação do Documento } & \multicolumn{1}{|c|}{ Tema } \\
\hline Ano III, no 22/ Abril de 1937 (página 6) & $\begin{array}{l}\text { Importância do Diploma de Arte- } \\
\text { Culinária }\end{array}$ \\
\hline Ano VII, no 23/ Maio de 1937 (página 6) & Vantagens do Curso de corte e costura \\
\hline Ano VII, no 54/ Julho de 1941 (página 3) & Uso de utensílios domésticos \\
\hline Ano VII, no 54/ Julho de 1941 (página 3) & $\begin{array}{l}\text { Importância da Arte-Culinária na } \\
\text { Educação da mulher }\end{array}$ \\
\hline Ano VII, $n^{\circ}$ 56/ Setembro de 1941 (página 4) & Arrumação da mesa para jantares \\
\hline
\end{tabular}

A Escola Normal Rural de Juazeiro do Norte, ainda de acordo com seu Regulamento, deveria criar e manter dez instituições desse tipo, quais sejam: a biblioteca, o museu, o clube agrícola, o caixa escolar, o círculo de pais e professores, a imprensa escolar, o clube de cultura física, o orfeon, a cooperativa e o pelotão da saúde (Decreto no . 1.269/1934, Art. 76). Aos alunos, cabia a função de colaborar na organização das instituições, participando da elaboração dos estatutos, arranjando os ambientes e preparando os móveis (Ibidem, Art. 77).

Nas fontes consultadas, as referências a estas instituições são extremamente exíguas. Mesmo no escrito "História da Escola Normal Rural de Juazeiro", de Amália Xavier de Oliveira (1984), alguns desses organismos 
não são mencionados, pelo menos, não explicitamente, como é o caso do Círculo de Pais e Professores e do Clube de Cultura Física.

O Museu Vilas Nova Portugal, conforme indica o Regulamento da Escola, deveria ser formado por coleções de objetos e de produtos industriais, comerciais e agrícolas da própria região, colhidos e renovados pelos alunos, na ocasião das excursões escolares. Deveria conter também, além de matérias-primas e produtos manufaturados regionais, os trabalhos mais interessantes e originais produzidos pelos próprios alunos no decorrer do ano letivo (Art. 80, parágrafo único).

Pelo regulamento da Escola Normal Rural de Juazeiro do Norte, o Círculo de Pais e Professores destinava-se a aproximar e estabelecer a colaboração entre família e escola. Esta instituição, de acordo com o Regulamento da escola, deveria reunir-se em caráter familiar, a fim de se inteirar dos trabalhos escolares, fazendo que, assim, a escola realizasse por completo sua missão social de educar, instruir e civilizar, melhorando a família e a sociedade (Art. 83, parágrafo único). Ao Clube de Cultura Física, por sua vez, cabia oferecer aos alunos a noção do dever pelo bemestar corporal, ensinando-lhes os meios de desenvolver o físico, para melhor servir moral e intelectualmente. Este órgão era também responsável por cuidar das excursões, passeios, exercícios e jogos (Ibidem, Art. 85, parágrafo único).

Quanto ao orfeônico, são inúmeras as menções de Amália Xavier a esta instituição no cotidiano da Escola. Sua finalidade central consistia no desenvolvimento do gosto pela boa música, cultivando o folclore em conjunto com a educação moral e artística, formando assim uma alma nacional (Decreto ${ }^{\circ}$ 1.269/1934, Art. 86). Por meio deste órgão, buscavase, ainda, promover "a expansão da simpatia e da solidariedade humana" (Ibidem, § único, Art.86).

As finalidades da biblioteca estavam voltadas para o "despertar, nos alunos, o gosto pela leitura e o espírito de pesquisa, facilitando, de maneira intuitiva e prática, o estudo de todas as matérias do programa escolar" (Decreto $\mathrm{n}^{\mathrm{o}} .1 .269,1934$, Art. 79), devendo ser acessível a todos os alunos -- Neste órgão, os alunos encontrariam livros, revistas, cartazes e gravuras, tendo um horário certo para consulta (Ibidem, parágrafos $2^{\circ}$ e $3^{\circ}$ ). Ligado à 
Biblioteca José Marrocos ${ }^{6}$ estava o Grêmio Literário Pe. José de Anchieta, criado em 05 de abril de 1934. Esta instituição era percebida pelos alunos e professores como de fundamental importância para o desenvolvimento da Escola, como comenta a professora Raimunda Cruz, em um discurso na posse da nova diretoria do Grêmio Pe. Anchieta:

Hoje, celebrando-se a posse da nova diretoria do Grêmio Literário - Pe. José de Anchieta, aproveito a oportunidade para falar-vos da necessidade e utilidade das instituições escolares que bem o compreendeis: são de capital importância para nossa vida de relação. [...]

O Grêmio Literário - Pe. Anchieta nos auxiliará nestas lutas; pois, a sua finalidade é desenvolver inteligências é incutir nos sócios o amor da Pátria, das artes e das letras; é portanto umas das mais importantes instituições entre a que se atiram dentro da Escola e que merece de modo especial o nosso apreço e acolhimento. [...] (Jornal O Lavrador, 1939, p. 2.)

Entre as atividades desenvolvidas pelo Grêmio Literário Pe. José de Anchieta, conforme apontam os registros de Amália Xavier de Oliveira (1984), estavam palestras, leitura de biografias e apresentação artística relacionada ao biografado, declamação de poesias, comemorações as mais diversas, entre outras. Os trechos transcritos são emblemáticos:

Comemoração do "Dia de Tiradentes" pelo Grêmio Pe. Anchieta. A oradora oficial, aluna Geni Machado, prendeu a atenção dos ouvintes, falando sobre Tiradentes o herói que sacrificou sua vida pelo mais nobre ideal que pode abrigar o coração de um brasileiro - a independência! [...]. O presidente escalou as alunas que deveriam falar sobre a data de $1^{\circ}$ de maio $[\ldots]$

Comemorando o "Dia do Trabalho" o Grêmio Pe. Anchieta se reúne, presentes os Corpos docente e discente da Escola e do Ginásio Diocesano do Crato naquele dia, em visita oficial à Escola Normal

${ }^{6} \mathrm{O}$ nome da biblioteca está estabelecido no Artigo $6^{\circ}$ do Estatuto do Grêmio Literário Pe. José de Anchieta, apresentado na última sessão da diretoria de 1939, datada de 14 de março de 1940 (OLIVEIRA, 1984, p. 112).

Educ. e Filos. Uberlândia, v. 23, n. 46, p. 99-118, jul./dez. 2009. 
Rural. O Secretário do Instituto Educacional então na direção do Estabelecimento, Dr. Jacinto Botelho, deu início a sessão, passando, em seguida a presidência ao aluno, José Sebastião Paixão, presidente do Grêmio. A Secretária Zareli Amorim leu a data e saudou os visitantes. Falaram ainda: Moacir Rodrigues, Glafira Landim e Emir landim. Marieta Cruz aluna do $2^{\circ}$ Primário, fez uma bela alocução sobre a data e foi muito aplaudida. [...] (OLIVEIRA 1984, p. 42).

O trecho demonstra que o Grêmio manteve ligações constantes com diversas unidades escolares do País e que dele participavam alunos e professores. Os registros de Oliveira (1984) evidenciam ainda a constante participação da direção da escola nas sessões desta instituição auxiliar da Escola.

A Liga da Amabilidade, embora não prevista no Regulamento da Escola, fez parte do cotidiano da Escola Normal Rural desde seus primeiros meses $^{7}$. Criada em 1934, tinha a finalidade de estabelecer a união entre as alunas, procurando desfazer quaisquer resquícios de ressentimento, que pudessem produzir rivalidade e discórdia; também era valorizado o respeito para com o próximo.

O Pelotão da Saúde tinha como fim desenvolver nos alunos, com a realização de palestras semanais, o cultivo de hábitos de higiene, como o asseio com o corpo, a prevenção de doenças, conforme evidencia a palestra ministrada pela aluna do $1^{\circ}$ ano complementar, Assunção Gonçalves, sobre a higiene das mãos:

$\mathrm{O}$ assunto sobre que venho tratar na sessão de hoje, diz respeito à higiene das mãos. Oferece meios para uma longa palestra. Não obstante não estenderei muito, e tratarei de massar o menos possível o meu distinto e paciente auditório. Considero a higiene das mãos umas das bases principais não só da nossa saúde, como da elegância, e mui especialmente da elegância feminina. Devemos, pois, trazer as mãos o mais bem cuidadas possível [...]. (Jornal O Lavrador, 1934, p. 6).

${ }^{7}$ O primeiro registro dessa instituição por Amália Xavier de Oliveira (1984, p. 30), datado de 27 de julho de 1934, se faz nos seguintes termos: "Nerci Matos noticia o pedido e aceitação de Dr. Justino Vilela, como sócio da Liga da Amabilidade".

Educ. e Filos. Uberlândia, v. 23, n. 46, p. 99-118, jul./dez. 2009. 
O Clube Agrícola foi uma instituição de destaque criada na Escola Normal Rural. Fundado em 13 de maio de 1934, recebeu o nome de Clube Agrícola Alberto Torres, conforme registra Oliveira (1984). Um dos objetivos do Clube era "dignificar o trabalho manual; elevar e engrandecer a vocação e a profissão do lavrador; incutir na consciencia de seus socios o amor à terra, o sentimento da nobreza das atividades agrícolas e a idéa de seu valor econômico e patriotico" (Decreto ${ }^{\circ}$. 1.269, 1934, Art. 81). Este órgão escolar recebia o apoio da Sociedade dos Amigos de Alberto Torres, mediante o repasse de materiais diversos, conforme mostra o trecho retirado do jornal $O$ Lavrador:

A nossa benemérita benfeitora, Sociedade dos Amigos de Alberto Torres, sempre encontra um meio prático e eficiente de despertar entre os jovens estudantes o amor às plantações. Além dos múltiplos benefícios que nos presta, enviando sementes e tudo mais que necessitamos, recebemos, ultimamente dois volumes de "Vida na roça" para premiar aos 2 alunos mais aplicados no cultivo das plantas do clube. José de França Farias e Aderson Braz foram os felizardos. (Jornal O Lavrador, 1934, p. 6).

As funções exercidas pelo Clube Agrícola Alberto Torres eram bastante diversificadas. Este órgão era prioritariamente composto pelos alunos, conforme indica Oliveira (1984), que, com auxílio da Diretoria da Escola, promoviam uma série de atividades rurais, tais como concursos sobre determinada cultura, comemorações diversas, como a Semana do Fazendeiro, o Dia do Feijão, o Dia do Milho, o Dia do Algodão etc. Estas comemorações eram promovidas pelos próprios membros do Clube Agrícola, que decidiam em reunião registrada em Ata, publicada freqüentemente no jornal $O$ Lavrador, como seria cada evento.

O Clube Agrícola da Escola Normal Rural tinham também a função de fundar outros clubes agrícolas nas escolas das regiões vizinhas, como mostra o trecho a seguir:

- Em 15 de julho o nosso Secretário fundou em Conceição do Cariri um Clube que vai em Franco Progresso e que conta com 60 socios.

Educ. e Filos. Uberlândia, v. 23, n. 46, p. 99-118, jul./dez. 2009. 
- A 26 do mesmo mês, a Diretoria do Clube acompanhando a comissão da Semana Ruralista, fundou em Barbalha, no Grupo Escolar, um núcleo com perto de 180 socios que, entusiasmados trocam as horas de brincadeira pelo constante progredir de seu Clube.

- Em Malvas, a 9 de agosto, a Diretoria e sócios do Clube "Alberto Torres fundaram um clube com 50 socios esforçados que muito tem plantado e com reais resultados. (Anais da Semana Ruralista, 1938, p. 141 e 142).

Constatou-se que o cotidiano escolar representado nas práticas pedagógicas e produtos materiais específicos que, proporcionavam uma formação diferenciada para o meio rural se constituíam através de relações (sempre sociais), que determinavam seus termos e que cada individualidade era um lugar onde atuava uma pluralidade incoerente (e muitas vezes contraditórias) de suas determinantes relacionais. Como diria Certeau (1994), o cotidiano se inventa de mil maneiras.

As fontes investigadas representam a materialização dos conhecimentos e práticas que visavam auxiliar a manutenção do homem no campo, através de um paternalismo autoritário que representava o brasileiro rural como "indefeso e impotente", porém como um homem passível de ser educado pela ação da escola. Os elementos apresentados até aqui mostram uma escola de formação de professores ruralistas que se constituiu como espaço de exercício de práticas no meio rural; uma instituição reconhecida como precursora, inovadora e redentora; um espaço de vivências, em que desejos, sonhos, conflitos e tudo o mais que é humano estavam presentes na tentativa de formar, reformar e disciplinar, marcada pelos valores de uma época que representa, na História da Educação, o período de consolidação das políticas e práticas de formação de professores no Brasil. Um tempo que merece ser constantemente relembrado e interpretado para auxiliar a compreender um país em constante desafio de educar.

\section{Referências}

CASTELO, Plácido Aderaldo. O Ensino Rural no Ceará. Fortaleza: Ed. Instituto do Ceará, 1951.

Educ. e Filos. Uberlândia, v. 23, n. 46, p. 99-118, jul./dez. 2009. 
História do Ensino no Ceará. Fortaleza: Imprensa Oficial, 1970.

CERTEAU, Michel de. A invenção do cotidiano: 1. Artes de fazer. Trad. Ephraim Ferreira Alves. Petrópolis, RJ: Vozes, 1994.

LOURENÇO FILHO, Manoel Bergström. A formação de Professores: da Escola Normal à Escola de Educação. Brasília-DF: INEP/MEC, 2001.

MAGALHÃES JUNIOR, Antonio Germano; FARIAS, Isabel Maria Sabino de. A imprensa escolar na formação de professores ruralistas: usos e significados de uma experiência. In: Educação UNISINOS/ Universidade Vale do Rio dos Sinos. Vol. 11, n. 3 (set./ dez. 2007). São Leopoldo: UNISINOS, 2007.

MENNUCCI, Sud. A Crise Brasileira de Educação. São Paulo: Editora Piratininga, 1934 . A Ruralização. São Paulo: Imprensa Oficial do Estado, 1944. . Pelo Sentido Ruralista da Civilização. São Paulo: Imprensa Graphica da "Revista dos Tribunais", 1935.

OLIVEIRA, Amália Xavier de. História da Escola Normal Rural de Juazeiro do Norte. Fortaleza: Secretaria de Cultura e desporto, 1984.

SOUZA, José Boaventura de. Escola Normal Rural de Juazeiro: uma experiência Pioneira. Juazeiro do Norte: IPESC, 1994, (Série Monografia, $\left.n^{\circ} 3\right)$.

SOUSA, Joaquim Moreira de. Sistema Educacional Cearense. Recife: MEC/INEP, 1961.

THERRIEN, Jacques; DAMASCENO, Maria Nobre (Coords.). Educação e Escola no Campo. Campinas: Papirus, 1993. 